\title{
Cultura Cultura
}

\section{Apresentação}

Fronteira, cosmopolitismo e nação nos mundos ibéricos e ibero-americanos

Apresentação

\section{Maria Fernanda de Abreu}

\section{OpenEdition}

\section{Journals}

\section{Edição electrónica}

URL: https://journals.openedition.org/cultura/4776

DOI: $10.4000 /$ cultura.4776

ISSN: 2183-2021

\section{Editora}

CHAM - Centro de Humanidades

\section{Edição impressa}

Data de publição: 1 janeiro 2018

Paginação: 9-11

ISSN: 0870-4546

\section{Refêrencia eletrónica}

Maria Fernanda de Abreu, «Fronteira, cosmopolitismo e nação nos mundos ibéricos e iberoamericanos », Cultura [Online], vol. 37 | 2018, posto online no dia 03 dezembro 2020, consultado o 09 julho 2021. URL: http://journals.openedition.org/cultura/4776 ; DOI: https://doi.org/10.4000/cultura. 4776

Este documento foi criado de forma automática no dia 9 julho 2021.

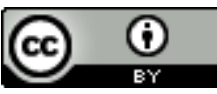

Cultura is licensed under a Creative Commons Atribuição 4.0 International. 


\title{
Apresentação
}

\section{Fronteira, cosmopolitismo e nação nos mundos ibéricos e ibero- americanos}

\author{
Apresentação
}

Maria Fernanda de Abreu

\section{NOTA DO AUTOR}

Preparado em 2018, este volume só foi impresso em 2020. Por esta razão, não podemos deixar de recordar que Renato Cordeiro Gomes, que tanto celebrou a publicação destes textos num número da revista Cultura, não possa tê-lo em suas mãos. Renato faleceu em Setembro de 2019. Esperamos ser-lhe fiel, sabemos que ficaria feliz e havemos de recordá-lo sempre com enorme gratidão e saudade. Professor e investigador de inexcedíveis qualidades científicas e humanas, desde há muito contávamos, no nosso grupo, com o seu saber, a sua sempre ponderada reflexão e a sua criatividade teórica e analítica.

1 Sob este título, publica-se, neste número da Cultura, um conjunto de textos que respondem ao projecto de aprofundar, tanto no plano teórico como no analítico, e de forma articulada, a operatividade destes três conceitos no conhecimento das diversas especificidades culturais desenvolvidas em territórios ibero-americanos e ibéricos: Fronteira, cosmopolitismo e nação.

2 Tivemos os nossos primeiros debates há quase uma década e, no Grupo de Investigação «Cultura, história e pensamento ibéricos e ibero-americanos», que então coordenávamos, começámos a dar-lhe forma em parceria com o Programa de PósGraduação em Literatura, Cultura e Contemporaneidade da PUC-RIO (Pontifícia Universidade Católica do Rio de Janeiro), através do nosso Colega e Amigo Renato Cordeiro Gomes. 
Guiava-nos uma das mais destacadas figuras dos estudos literários e culturais brasileiros: Silviano Santiago, escritor, ensaísta, professor. Por essa razão, o primeiro encontro conjunto, para dar conta do trabalho feito até aí, foi um simpósio em sua homenagem, realizado nos dias 20, 21 e 22 de Abril de 2015, que teve lugar em Lisboa, na NOVA FCSH, com a presença de um grupo de professores e investigadores

portugueses, brasileiros espanhóis.
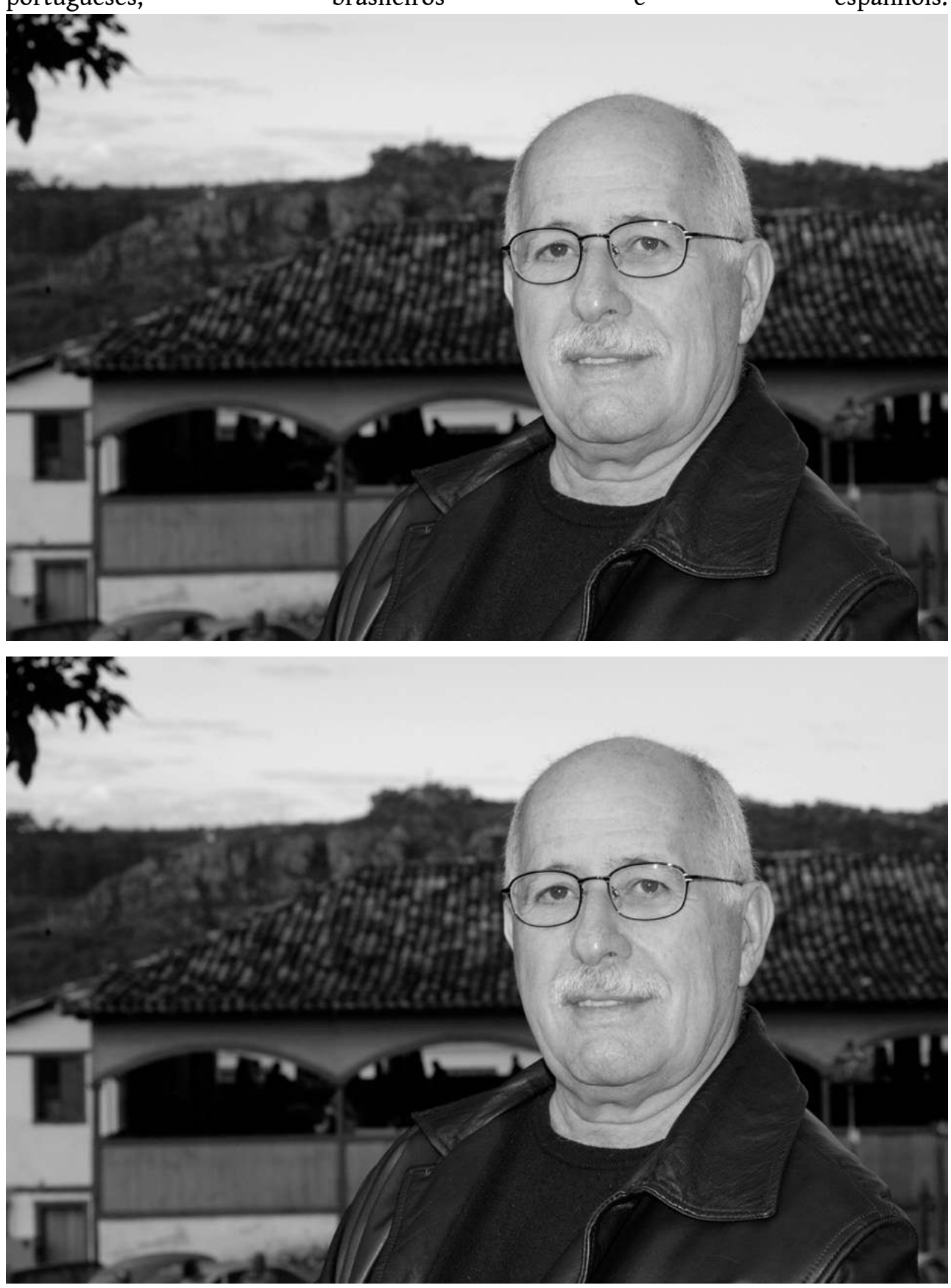

(C) Cláudio Nadair

3 Profundo conhecedor da obra de Silviano Santiago e do magistério que este exercia em várias gerações de ensaístas, seu aluno, colega e amigo (publicou Ensaios Antológicos de Silviano Santiago, 2013), Renato Cordeiro Gomes pôs todo o seu saber e empenho nesta homenagem, convidando para este simpósio prestigiados colegas, e também ex-alunos, vozes mais consolidadas umas, mais jovens outras, de um Brasil universitário que 
investiga e celebra a cultura. A eles, juntaram-se vozes de um Portugal que está atento e exalta o saber e a experiência vivida que nos vem daqueles mundos.

Silviano Santiago é um ensaísta e romancista brasileiro, figura cimeira da vida intelectual e universitária do seu país, internacionalmente reconhecida. Quatro vezes galardoado com o Prémio Jabuti nas categorias de romance e conto, recebeu, em 2013, o prestigioso Prémio Machado de Assis pelo conjunto da sua obra, outorgado pela Academia Brasileira de Letras e, em 2014, o Prémio Ibero-americano de Literatura José Donoso (Chile). Venceu ainda o Prémio Oceanos de Literatura em Língua Portuguesa, com o romance Mil Rosas Roubadas, em 2015.

Doutorado em Literatura Francesa pela Universidade de La Sorbonne, é Chevalier dans l'Ordre des Palmes Académiques e Officier dans l'Ordre des Arts et Lettres, de França. Foi professor nas universidades de New Mexico, Rutgers, Toronto, Nova Iorque, Buffalo, Indiana e Pontifícia Universidade Católica do Rio de Janeiro. É professor emérito da Universidade Federal Fluminense.

Entre os seus livros de ficção destacam-se: Em liberdade, Stella Manhattan, O falso mentiroso, Heranças, Machado, e os livros de contos Keith Jarrett no Blue Note, Histórias mal contadas e Anônimos. Das suas colectâneas de ensaios, onde propõe conceitos e metodologias fundamentais para a análise das culturas latino-americanas, destacam-se: Uma literatura nos trópicos, o cosmopolitismo do pobre, As raízes e o labirinto da América Latina e Genealogia da Ferocidade (análise da obra Grande Sertão: Veredas de Guimarães Rosa).

7 Coordenou e prefaciou os três volumes de Intérpretes do Brasil, e foi co-editor da correspondência de Carlos Drummond de Andrade e Mário de Andrade.

8 Não deixou Silviano Santiago de conjugar a escrita ficcional com a ensaística. A crescente tradução dos seus ensaios em países como Argentina e Chile testemunha o interesse que a sua obra desperta neste nosso tempo e, em particular, no âmbito dos estudos culturais, tendo já em preparação um volume onde se reúnem alguns dos seus ensaios mais destacados a ser publicados pela Companhia das Letras: 35 ensaios de Silviano Santiago.

Precisamente porque se nos afigurou de riquíssima utilidade analítica no conhecimento da diversidade e riqueza culturais características dos territórios ibero-americanos e ibéricos, entre outros, conceitos como o de cosmopolitismo do pobre ou ferramentas metodológicas como o entre-lugar do discurso latino-americano, propostos, desenvolvidos e aplicados por Silviano Santiago, e porque a história política e das ideias dos últimos anos tem mostrado e incrementado o valor daquelas hipóteses que, então, nos foi tão evidente, decidimos continuar a aprofundar aqueles primeiros trabalhos nos textos que se reúnem neste volume.

Lisboa, Dezembro de 2018 